\title{
A Rare Giant Pulmonary Aneurysm with Left Lung Compression: A Case Report with Insights from the Literature
}

\author{
Fan He, Huaidong Chen, Ximing Qian \\ Department of Cardiac Surgery, Sir Run Run Shaw Hospital, School of Medicine, Zhejiang University, Hangzhou, China
}

\section{ABSTRACT}

Pulmonary artery aneurysm (PAA) is a rare condition that results from several pathologies. Here, we report a case of a rare giant PAA accompanied by left lung compression due to recurrent chest tightness for $>13$ years. Through this case and review of the literature, we explore the treatment options to improve the diagnosis and treatment of PAA. We found that patients with PAA may survive longer even if they also have pulmonary hypertension. In addition, it is recommended that if a PAA diameter is $>5.5 \mathrm{~cm}$ or if the PAA diameter has increased by $>0.5 \mathrm{~cm}$ in 6 months, the PAA should be operated on as soon as possible. Conservative treatment can be recommended in patients with congenital PAA if pulmonary arterial pressure is normal.

\section{INTRODUCTION}

Pulmonary artery aneurysm (PAA) is a rare disease with only $0.0073 \%$ morbidity, and the ratio of morbidity for aortic aneurysms is approximately 1:250 [Deterling 1947]. The cause of PAA is typically related to congenital heart disease, pulmonary hypertension $(\mathrm{PH})$, systemic vasculitis, infection, and/or trauma [Deb 2005; Nguyen 2007; Camargo 2010; Koch 2010; Shankarappa 2010; Araújo 2011; Theodoropoulos 2013]. The common symptoms of PAA include chest tightness, laborious dyspnea, hemoptysis, cough, and chest pain; however, the disease lacks typical clinical manifestations [Fujiwara 1992; Veldtman 2003; Smalcelj 2005; Shankarappa 2010; Theodoropoulos 2013; Galiè 2017]. In most patients, it is often accidentally discovered because of a physical examination or during other illnesses. As a result, the natural course of PAA often cannot be determined. Early diagnosis and treatment are difficult, so patients may have a long history, and tumors may be unusually large when PAA is confirmed. Therefore, it is a difficult disease to cure. Here, we report the case of a rare giant PAA accompanied by left lung compression due to recurrent chest tightness for $>13$ years. For this case, we reviewed the literature to improve the diagnosis and treatment of PAA.

Received December 3, 2018; accepted Fanuary 26, 2019.

F.H. and H.C. are co-first authors.

Correspondence: Ximing Qian, Department of Cardiac Surgery, Sir Run Run Shaw Hospital, School of Medicine, Zhejiang University, Hangzhou, China (3310005@zju.edu.cn).

\section{CASE REPORT}

A 56-year-old female patient was admitted to our hospital because of recurrent chest tightness for more than 13 years, with aggravation of the tightness for half a month. The patient suffered from sudden chest tightness and shortness of breath after eating for 1 day before admission, which resulted in dyspnea, palpitation, and sweating, and was admitted to our hospital in an emergency.

The physical examination showed that the patient was in acute distress and had orthopnea, slight cyanosis of lips and mouth, filling of jugular vein, edema of lower limbs. Both lungs sounded coarse, with moist crackles dispersing; the heart boundary was enlarged; and the windlike noises of the systolic period can be heard in the second-third intercostal space of the left margin of the sternum. Examination of pulmonary artery (PA) CTA after admission showed that the PA widened and the PA trunk had a tumorlike dilation. The diameter of the main PA was about $16.1 \times 17.3 \mathrm{~cm}$, and the diameter of the left and right pulmonary arteries was about $3 \mathrm{~cm}$ and $2.8 \mathrm{~cm}$. respectively? No obvious embolism was observed in the bilateral pulmonary arteries. The heart was expanded, and the superior and inferior venae cavae were enlarged (Figure 1). The echocardiography showed a severe pulmonary valve insufficiency with mild pulmonary hypertension and pulmonary aneurysmal dilatation; the expansion range was about $89.4 \times 69.6 \mathrm{~mm}$. The right atrium had an enlargement with $84.9 \times 79.3 \mathrm{~mm}$, and the inferior vena cava was widened with an internal diameter of about $26.8 \mathrm{~mm}$ (Figure 2). Electrocardiogram indicated atrial fibrillation. After admission, arterial blood gas examination showed $\mathrm{pH} 7.462$, carbon dioxide partial pressure (PCO2) $39.7 \mathrm{mmHg}$, oxygen partial pressure (PO2) $49.8 \mathrm{mmHg}$, and the result of ProBNP examination was $4523 \mathrm{pg} / \mathrm{mL}$.

The diagnoses were pulmonary aneurysm and severe pulmonary valve insufficiency, caused by pulmonary hypertension, and associated with right heart failure and respiratory failure (type I). At the same time, the patient had atrial fibrillation.

The patient was given oxygen inhalation, diuresis, dopamine, and other treatments after admission, and the symptoms of difficulty breathing and edema were alleviated. Reexamination of blood gas indicated increased $\mathrm{PO} 2$ and decreased PCO2. Before operation, the patient was given a Swan-Ganz catheter examination. The results revealed the PA pressure was $77 / 19 \mathrm{mmHg}$ and the aortic blood pressure at the same time was $90 / 68 \mathrm{mmHg}$; the results also indicated the $\mathrm{SpO} 2$ was $67 \%$ and the heart rate was 83 beats per minute. 


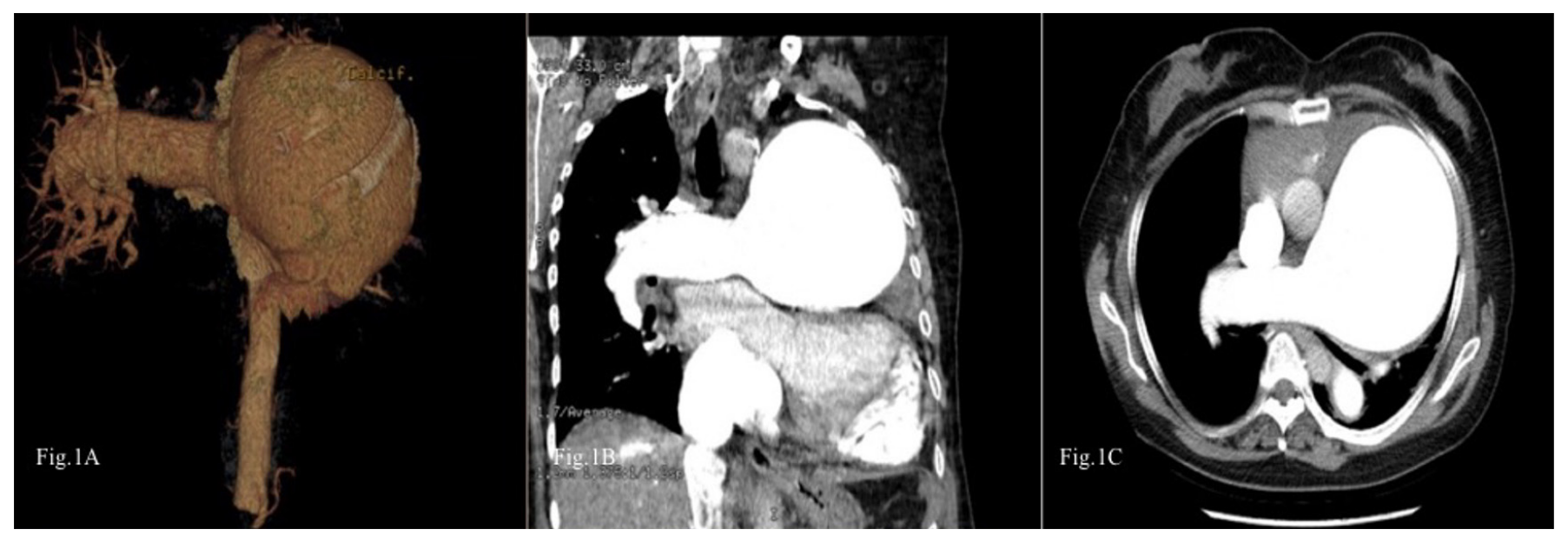

Figure 1. Pulmonary artery (PA) CTA showing PA enlargement and pulmonary aneurysmal dilatation.

Considering the patient's high PA pressure and hypoxemia, the risk of operation was higher. As a result, the surgical treatment was abandoned by the patient. And then she was given continued conservative treatment, and the blood gas reexamination after 2 weeks indicated $\mathrm{pH} 7.454$, PCO2 $36 \mathrm{mmHg}$, PO2 $86 \mathrm{mmHg}, \mathrm{PaO} 2 / \mathrm{FiO} 2$ ratio 215. The patient had significantly improved symptoms and was discharged from the hospital for medical treatment.

\section{DISCUSSION}

The incidence of PAA is extremely low. In 1945, Deterling and Clagett [Deterling 1947] found an incidence of only $0.0073 \%$ in 109,571 autopsies. Currently, there is no unified definition for PAA. With use of CT, the upper limit of the main PA diameter in adults is $29 \mathrm{~mm}$, and the upper limit of the interlobular PA is $17 \mathrm{~mm}$ [Fraser 1999]. Thus, Nguyen et al [Nguyen 2007] indicated that a diagnosis of PAA could be made if PA dilatation exceeded the normal upper limit. Brown [Brown 2008] defined PAA as a PA with a diameter of $>40 \mathrm{~mm}$ so as to distinguish PA dilatation from pulmonary aneurysm. However, these 2 definitions do not account for body size differences among individuals or the diameter of the other blood vessels in the body. Consequently, some academics [Shankarappa 2010; Galiè 2017] believe that an aneurysm diameter of $>4 \mathrm{~cm}$ or ratio of aneurysm diameter to body surface area of $\geq 2.4 \mathrm{~cm} / \mathrm{m}^{2}$ and a PA-to-aorta diameter ratio of $>1.5$ are more ideal for a diagnosis of PAA. In addition, some scholars considered sex differences and defined PAA as a PA diameter of $>43.4 \mathrm{~mm}$ in females and $>40.4 \mathrm{~mm}$ in males or 1.5 times greater than the normal diameter of the PA [Shankarappa 2010; Truong 2010; Kim 2013; Duijnhouwer 2016; Reisenauer 2017]. On the basis of the above diagnosis, Reisenauer et al [Reisenauer 2017] further subdivided PAA into "giant" and "large" pulmonary aneurysms. PA diameter of $>8 \mathrm{~cm}$ was defined as a "giant" pulmonary aneurysm, and a diameter of 5-8 cm was defined as a "large" pulmonary aneurysm. As shown by our patient's CTA in the present study, the PA diameter had reached $16 \mathrm{~cm}$, which is rare in the published literature, and the diameter reported in most cases is $5-10 \mathrm{~cm}$. So, what is causing the tumor to be so large?

The diagnosis of PAA is often discovered accidentally because of a physical examination or illness. Therefore, the natural pathogenesis of PAA is unknown, and the exact cause of PAA is sometimes unclear. Reports have shown that congenital heart disease or infectious factors (syphilis, mucedine, and tuberculosis) account for two thirds of the reported cases of PAA [Theodoropoulos 2013; Reisenauer 2017]. Other rare causes include degenerative valvular disease, $\mathrm{PH}$, iatrogenic factors, lung cancer, systemic vasculitis (Behcet disease, giant cell arteritis), connective tissue disease (Marfan syndrome, Hughes-Stovin syndrome), chest trauma, and idiopathic PAAs; among these, congenital heart defects account for 50\% [Luchtrath 1981;Deb 2005; Nguyen 2007; Shih 2007; Garcia 2008; Baztarrica 2010; Camargo 2010; Shankarappa 2010; Araújo 2011; Seguchi 2011; Sargur 2014; Reisenauer 2017]. In a small sample study of 38 patients with PAA, 36 cases $(95 \%)$ were due to congenital heart disease, of which the most common cause was pulmonary valve regurgitation (29\% in 11 cases) [Reisenauer 2017]. However, it is important to note that PA trunk dilatation can also cause secondary pulmonary valve regurgitation [Garcia 2008]. As in the present case, the PA of the patient had obvious enlargement when he was diagnosed with PAA. Owing to the lack of original imaging data, we are not clear regarding whether pulmonary valve regurgitation was a primary or secondary change.

PAA lacks typical clinical manifestations, and some patients may have no obvious clinical manifestations. The emergence of clinical symptoms is usually associated with complications such as cough and difficulty in breathing due to bronchial or tracheal compression, acute coronary syndrome, or sudden cardiac death due to compression of the left coronary artery [Fujiwara 1992; Galiè 2017]. In addition, if the aneurysm is large and local blood flow is slow, there is a possibility of intravascular mural thrombus formation. Moreover, fever is common in mycotic PAA. Secondary to PAA, the right atrium enlargement, right ventricular hypertrophy, right heart failure, 


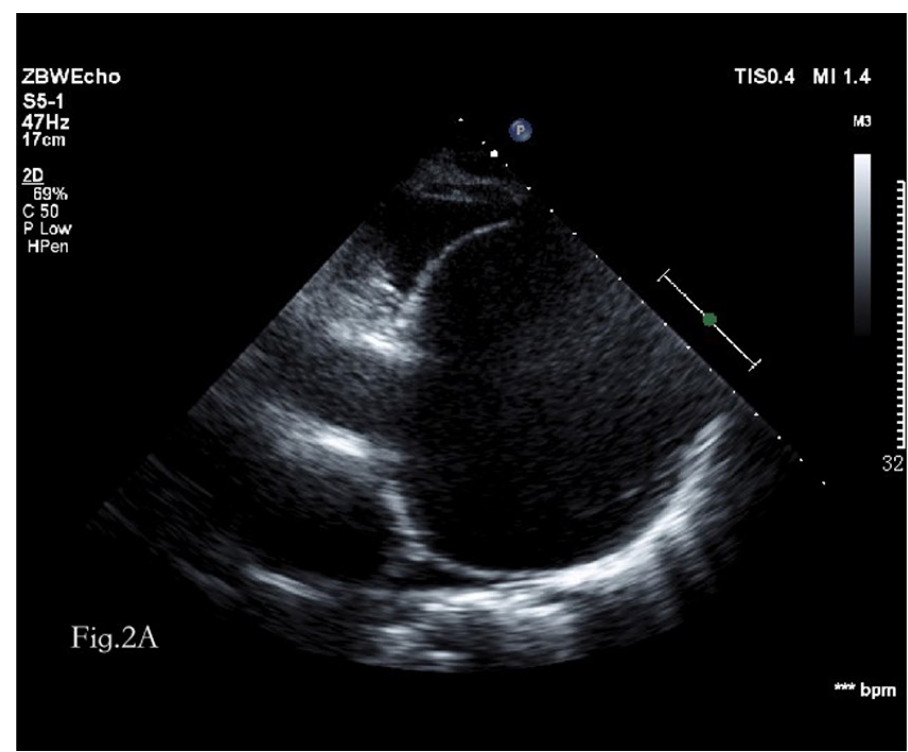

ZBWEcho
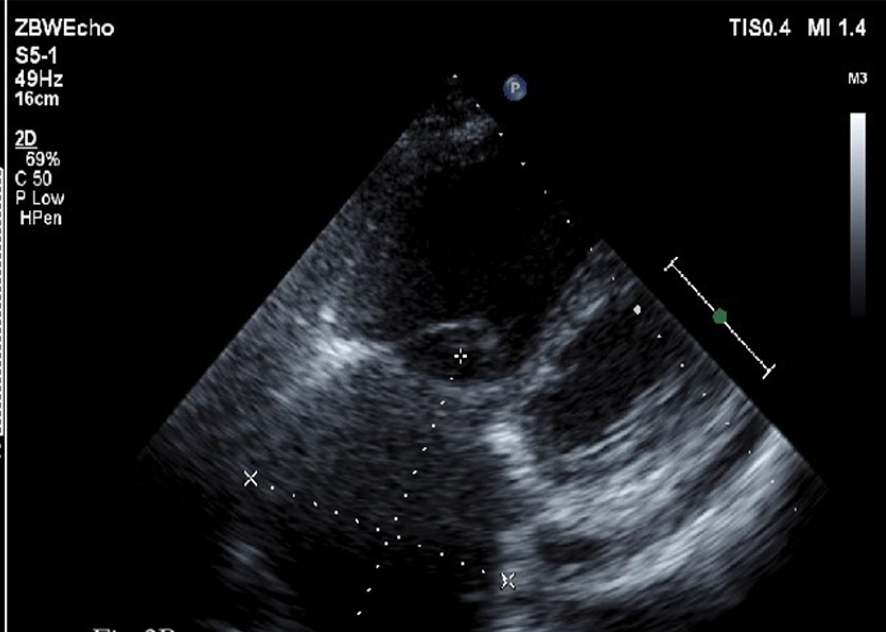

Figure 2. Echocardiography showing a pulmonary aneurysmal dilatation (Fig.2A) and right atrial enlargement (Fig.2B).

pericardial effusion, and pleural effusion can be detected, and the systolic murmurs of the second-third intercostal space can be detected by auscultation [Smalcelj 2005; Shankarappa 2010; Seguchi 2011]. The most serious risk of PAA is the formation of PA dissection (PAD), which is usually associated with PH [27 Luchtrath 1981], and hemoptysis may be an early warning sign of aneurysm rupture [Tsui 2001; Shih 2007]. It has been reported that $66 \%$ of patients with PAD have PA hypertension, and only $19 \%$ of patients with PAD have no PH [Inayama 2001]. In the present case, the patient's initial symptoms 13 years earlier were chest tightness and shortness of breath after exercise, which were relieved after rest, and appeared repeatedly thereafter. When the patient was admitted to our hospital, she presented with chest tightness, dyspnea, cough, and right heart failure concurrently; there were no main complaints such as hemoptysis or pain in the anterior cardiac region; and the $\mathrm{PA}$ pressure was $77 \mathrm{mmHg}$. Because the symptoms were atypical, they were not noticed by the patient, and thus, treatment was not timely. As a result, the diameter of the PA reached $16 \mathrm{~cm}$. Severe PH (systemic arterial blood pressure of $90 / 68 \mathrm{mmHg}$ at the same time) appearing simultaneously with left lung compressible atelectasis brought numerous difficulties in treating our patient.

So far, there is no definite guideline for the surgical treatment of PAA. Most scholars believe that there are different treatment strategies for aneurysms in the situation of low or high pulmonary artery pressure [Tami 1994; Fakler 2008]. For patients with $\mathrm{PA}$ diameter of $>55 \mathrm{~mm}$ and $\mathrm{PH}$, the biggest risks are sudden death (perhaps due to PAD) and left main coronary artery compression [ yłkowska 2012]. In their metaanalysis, Duijnhouwer et al indicated that $62 \%$ of PAA dissections were associated with high-pressure aneurysms [Duijnhouwer 2016]. For low-pressure aneurysms, even if the tumor was large, the incidence of PAA dissection was very low after several years of follow-up [Chen 1996, Fakler 2008; Ercan
2014]. Therefore, most scholars recommend immediate surgical treatment for patients with obvious $\mathrm{PH}$, particularly those who have already developed symptoms, and most scholars recommend aggressive surgical treatment is necessary for patients with PA diameter of $>55 \mathrm{~mm}$ [Imazio 2004; Kreibich 2015]. Other scholars agree that all patients with PA of $>8$ $\mathrm{cm}$ need surgical treatment, regardless of their PA pressure [6 Camargo 2010]. At present, surgical procedures mainly comprise aneurysm suture or angioplasty, allograft material, or artificial material transplantation [Caralps 1978; Hamawy 2002]. For our patient, we initially established procedures for pulmonary valve replacement and main PA artificial vascular replacement. However, she had stubborn hypoxemia perioperatively, which was possibly associated with left lung compression. We performed Swan-Ganz catheterization, which revealed severe $\mathrm{PH}$ with $\mathrm{PA}$ pressure of $77 / 19 \mathrm{mmHg}$ and concurrent aortic blood pressure of $90 / 68 \mathrm{mmHg}$. Because of his $\mathrm{PH}$ and hypoxemia, we advised the patient regarding the operation plan and possible complications, as well as possible benefit of surgical treatment for long-term survival; however, the patient eventually refused to undergo surgery. Of course, after the reduction of PA pressure through conservative treatment, we will recommend surgical treatment for patients as soon as possible.

Although reports have shown that patients with PAA live longer without surgery, surgical treatment may be beneficial for long-term survival. For our case, the patient had a long illness history, and the PA diameter had reached $17 \mathrm{~cm}$, which is rarely reported in the literature. The risk of postoperative death is very high in patients, like our case, with large PAA [Kreibich 2015]. In addition, the patient had severe left lung atelectasis, the specific history of which was unknown, with the incidence of ischemia-reperfusion injury in the left lung and stubborn hypoxemia increasing significantly after surgical resection of the aneurysm. In terms of surgical results, 
mortality and morbidity data could not be provided because there were few large sample studies of PAA. Further, studies have shown that the risk of complications during the perioperative period of PAA is comparable to that for aortic aneurysm surgery [Kreibich 2015]. In view of the above considerations, the patient opted to not undergo surgery.

For future research, for these patients with severe $\mathrm{PH}$ and ischemia-reperfusion injury, who cannot be cured by surgery, lung transplantation may be able to provide a complete choice for patients and surgeons.

\section{CONCLUSION}

In conclusion, we have learned the following lessons from this case:

(1) Patients with PAA may survive longer even if they also have $\mathrm{PH}$.

(2) With the results from our research combined with the current literature reports, we recommend the following treatment principles for patients with PAA:

(a) With reference to the guidelines for aortic disease, it is recommended that a PAA diameter of $>5.5 \mathrm{~cm}$ should be operated on as soon as possible [Kreibich 2015].

(b) If the PAA diameter has increased by $>0.5 \mathrm{~cm}$ in 6 months, it should be operated on as soon as possible [Kreibich 2015].

(c) For patients with PAA diameter of $>8.0 \mathrm{~cm}$, pulmonary aneurysm resection and replacement are recommended to avoid aneurysm recurrence [Butto 1987].

(d) For patients with stable pulmonary aneurysms with a diameter of $<5 \mathrm{~cm}$, CT or echocardiogram should be regularly performed to exclude aneurysm enlargement or $\mathrm{PH}$ [Reisenauer 2017].

(e) Surgical treatment is recommended for patients with compression of the adjoining structures [Kreibich 2015] or mural thrombus formation within aneurysms, particularly with PA dissection or rupture risk factors (such as $\mathrm{PH}$, connective tissue disease), regardless of aneurysm diameter [Chen 1996; Deb 2005; Kreibich 2015].

(f) For patients with symptoms of pulmonary valve regurgitation and right ventricular expansion, the timing of surgical intervention should be chosen according to the change in right ventricular size and right ventricular function rather than the diameter of the PAA [Fakler 2008; Iosifescu 2012].

(g) Interventional embolization may be effective in patients with peripheral vascular dilatation and massive hemoptysis [Galiè 2017].

(h) Conservative treatment can be recommended in patients with congenital PAA if pulmonary arterial pressure is normal [Vural 2007].

(3) If the patient has already developed pulmonary atelectasis from compression combined with refractory hypoxemia, the risks and benefits of surgery will not be clear. Conservative treatment may be more desirable at this point, unless lung transplantation is performed.

\section{ACKNOWLEDGMENTS}

This work was supported by a grant from The National Key Research and Development Program of China (no. 2017YFC1308004).

\section{REFERENCES}

Araújo I, Escribano P, Lopez-Gude MJ, et al. 2011. Giant pulmonary artery aneurysm in a patient with vasoreactive pulmonary hypertension: a case report. BMC Cardiovasc Disord 11:64.

Baztarrica GP, Bevacqua F, Porcile R. 2010. Aneurisma de la arteria pulmonar = Pulmonary artery aneurysm. Rev Esp Cardiol 63(2):240-1. Spanish, English.

Brown JR, Plotnick G. 2008. Pulmonary artery aneurysm as a cause for chest pain in a patient with Noonan's syndrome: a case report. Cardiology 110(4):249-51.

Butto F, Lucas RV Jr, Edwards JE. 1987. Pulmonary arterial aneurysm: a pathologic study of five cases. Chest 91:237-41.

Camargo J, Camargo SM, Machuca TN, Bello RM. 2010. Large pulmonary artery pseudoaneurysm due to lung carcinoma: pulmonary artery pseudoaneurysm. J Thorac Imaging 25(1):W4-5.

Caralps JM, Bonnin JO, Oter R, Aris A. 1978. True aneurysm of the main pulmonary artery: surgical correction. Ann Thorac Surg 25(6):561-3.

Chen YF, Chiu CC, Lee CS. 1996. Giant aneurysm of main pulmonary artery. Ann Thorac Surg 62(1):272-4.

Deb SJ, Zehr KJ, Shields RC. 2005. Idiopathic pulmonary artery aneurysm. Ann Thorac Surg 80(4):1500-2.

Deterling RA Jr, Clagett OT. 1947. Aneurysm of the pulmonary artery: review of the literature and report of a case. Am Heart J , 34(4):471-99.

Duijnhouwer AL, Navarese EP, Van Dijk AP, Loeys B, Roos-Hesselink JW, De Boer MJ. 2016. Aneurysm of the pulmonary artery, a systematic review and critical analysis of current literature. Congenit Heart Dis 11(2):102-9.

Ercan S, Dogan A, Altunbas G, Davutoglu V. 2014. Giant pulmonary artery aneurysm: 12 years of follow-up. Case report and review of the literature. Thorac Cardiovasc Surg 62(5):450-2.

Fakler U, Mebus S, Kaemmerer H, et al. 2008. A ticking time bomb-high pressure pulmonary artery aneurysm. Am J Med 121(9):777-80.

Fraser RS, Müller NL, Colman N, Paré PD. c1999. Fraser and Paré's diagnosis of diseases of the chest. 4th ed. Philadelphia (PA): W.B. Saunders. Pulmonary hypertension and edema; p. 1935-7.

Fujiwara K, Naito Y, Higashiue S, et al. 1992. Left main coronary trunk compression by dilated main pulmonary artery in atrial septal defect. Report of three cases. J Thorac Cardiovasc Surg 104(2):449-52.

Galiè N, Saia F, Palazzini M, et al. 2017. Left main coronary artery compression in patients with pulmonary arterial hypertension and angina. $\mathrm{J}$ Am Coll Cardiol 69(23):2808-17.

Garcia A, Byrne JG, Bueno R, Flores RM. 2008. Aneurysm of the main pulmonary artery. Ann Thorac Cardiovasc Surg 14:399-401.

Hamawy AH, Cartledge RG, Girardi LN. 2002. Graft repair of a pulmonary artery aneurysm. Heart Surg Forum 5(4):396-8.

Imazio M, Cecchi E, Giammaria M, et al. 2004. Main pulmonary 
artery aneurysm: a case report and review of the literature. Ital Heart J $5(3): 232-7$.

Inayama Y, Nakatani Y, Kitamura H. 2001. Pulmonary artery dissection in patients without underlying pulmonary hypertension. Histopathology $38(5): 435-42$

Iosifescu AG, Doroban u LF, Anca TM, Iliescu VA. 2012. Surgical treatment of a pulmonary artery aneurysm due to a regurgitant quadricuspid pulmonary valve. Interact Cardiovasc Thorac Surg 14(6):880-2.

Kim JK, Seol SH, Kim TJ, et al. 2013. Low pressure pulmonary artery aneurysm with atrial septal defect. J Cardiovasc Ultrasound 21(2):94-5.

Koch A, Mechtersheimer G, Tochtermann U, Karck M. 2010. Ruptured pseudoaneurysm of the pulmonary artery--rare manifestation of a primary pulmonary artery sarcoma. Interact Cardiovasc Thorac Surg 10(1):120-1

Kreibich M, Siepe M, Kroll J, Höhn R, Grohmann J, Beyersdorf F. 2015. Aneurysms of the pulmonary artery. Circulation 131(3):310-6.

Lüchtrath H. 1981. Dissecting aneurysm of the pulmonary artery. Virchows Arch A Pathol Anat Histol 391(2):241-7.

Nguyen ET, Silva CI, Seely JM, Chong S, Lee KS, Müller NL. 2007. Pulmonary artery aneurysms and pseudoaneurysms in adults: findings at CT and radiography. AJR Am J Roentgenol 188(2):W126-34.

Reisenauer JS, Said SM, Schaff HV, Connolly HM, Maleszewski JJ, Dearani JA. 2017. Outcome of surgical repair of pulmonary artery aneurysms: a single-center experience with 38 patients. Ann Thorac Surg 104(5):1605-10.

Sargur R, Sudarshana Murthy KA. 2014. Pulmonary artery aneurysm - report of a case and review of literature. J Cardiovasc Med Cardiol 2(1):29-31.

Seguchi M, Wada H, Sakakura K, et al. 2011. Idiopathic pulmonary artery aneurysm. Circulation 124(14):e369-70.
Shankarappa RK, Moorthy N, Chandrasekaran D, Nanjappa MC. 2010. Giant pulmonary artery aneurysm secondary to primary pulmonary hypertension. Tex Heart Inst J 37(2):244-5.

Shih HH, Kang PL, Lin CY, Lin YH. 2007. Main pulmonary artery aneurysm. J Chin Med Assoc 70(10):453-5.

Smalcelj A, Brida V, Samarzija M, Matana A, Margetic E, Drinkovic N. 2005. Giant, dissecting, high-pressure pulmonary artery aneurysm: case report of a 1-year natural course. Tex Heart Inst J 32(4):589-94.

Tami LF, McElderry MW. 1994. Pulmonary artery aneurysm due to severe congenital pulmonic stenosis: case report and literature review. Angiology 45(5):383-90.

Theodoropoulos P, Ziganshin BA, Tranquilli M, Elefteriades JA. 2013. Pulmonary artery aneurysms: four case reports and literature review. Int J Angiol 22(3):143-8.

Truong QA, Massaro JM, Rogers IS, et al. 2010. Age and gender-specific pulmonary artery measurements by multi-detector computed tomography: Framingham Heart Study. J Am Coll Cardiol 55(10 suppl):A71. E665.

Tsui EY, Cheung YK, Chow L, Chau LF, Yu SK, Chan JH. 2001. Idiopathic pulmonary artery aneurysm: digital subtraction pulmonary angiography grossly underestimates the size of the aneurysm. Clin Imaging 25(3):178-80.

Veldtman GR, Dearani JA, Warnes CA. 2003. Low pressure giant pulmonary artery aneurysms in the adult: natural history and management strategies. Heart 89(9):1067-70.

Vural AH, Türk T, Ata Y, Göncü T, Ozyazicioglu A. 2007. Idiopathic asymptomatic main pulmonary artery aneurysm: surgery or conservative management? A case report. Heart Surg Forum 10(4):E273-5.

Żyłkowska J, Kurzyna M, Florczyk M, et al. 2012. Pulmonary artery dilatation correlates with the risk of unexpected death in chronic arterial or thromboembolic pulmonary hypertension. Chest 142(6):1406-16. 